\title{
Are there so many congeneric species of chironomid larvae in a small stream?
}

\author{
Narcís PRAT, ${ }^{1}$ Eduard M. GARCÍA-ROGER ${ }^{2 *}$ \\ ${ }^{1}$ Freshwater Ecology and Management Research Group, University of Barcelona; ${ }^{2}$ Cavanilles Institute of Biodiversity and Evolutionary \\ Biology, University of Valencia, Spain \\ *Corresponding author: eduardo.garcia@uv.es
}

\begin{abstract}
The co-occurrence of larvae of congeneric chironomid species is common in natural stream assemblages, and raises the problem of finding mechanisms to explain the co-existence of species with similar ecological requirements. In this contribution, we explored the co-occurrence of chironomid larvae belonging to congeneric species within four genera of chironomids: Cricotopus, Eukiefferiella, Orthocladius and Rheocricotopus (with 2, 7,2 and 4 species, respectively) in the headwaters of a small Mediterranean calcareous stream. Due to the intrinsic, natural spatial and temporal variability in these habitats, we studied three different sites at two different seasons within the annual hydrological cycle (spring vs summer samples), and each microhabitat unit was surveyed with an effort proportional to its cover at the sampling site. The Outlying Median Index method was used to distinguish the niches of the different chironomid species in relation to the hydraulic features and substrates within each site. Our results showed that hydraulic features helped to improve discrimination between the niches of five congeneric species of Eukiefferiella, and the same occurred within the species belonging to Cricotopus and Orthocladius, although niche overlap was high in general. One Rheocricotopus species was associated to algal substrate. Schoener's co-occurrence at the microhabitat scale was low among the congeneric species found in our study, suggesting exclusion mechanisms. Flow regime, substrate type and shifts in environmental conditions may favor the settlement of some species to the detriment of other congeneric ones, but other mechanisms such as lottery competition, diffusion competition or predation should be considered in further studies.
\end{abstract}

Key words: Chironomids; congeneric species; co-occurrence; hydraulics; niche; microhabitat.

Received: January 2018. Accepted: April 2018.

This paper was presented at the $20^{\text {th }}$ International Symposium on Chironomidae, Trento, Italy, 2-8 July 2017. Session: Autecology and Physiology.

\section{INTRODUCTION}

Chironomid larvae are known to be among the mostbroadly distributed, species-rich and abundant group of invertebrates in freshwater benthic samples (Pinder, 1986; Puntí et al., 2007). Despite the fact that different species within the Chironomidae family are known to exhibit variable responses to environmental gradients during the larval stage (Lencioni and Rossaro, 2005; Rossaro et al., 2006; Puntí et al., 2009), the co-occurrence of closerelated, mainly congeneric, species of chironomid larvae is often found in observational study field samples (Pinder, 1992; Tokeshi, 1995; Syrovátka et al., 2009). Due to morphological similarity and close phylogenetic relationship, the ecological niches of such congeneric species should be similar (i.e. niche retention; Wiens et al., 2010), thus leading to a huge niche overlap and strong competition (Violle et al. 2014). Therefore, in consideration of the well-established principle of competitive exclusion (Gause, 1934; for chironomid larvae see McLachlan, 1993), it is challenging to explain how congeneric chironomid species, with such similar ecological requirements, could co-exist.
In general, when two species co-occur in an area, further investigation is necessary to establish whether or not they actually occur together in the same habitat (i.e. syntopy; Rivas, 1964). But even within the same habitat, factors that could explain that co-existence might occur at the microhabitat scale (i.e. small, specialized habitats within larger habitats). In streams, microhabitat features such as the mosaic nature of the substrate (Minshall and Minshall, 1977; Beisel et al., 2000), the local hydraulic conditions (Chutter, 1969; Statzner et al., 1988; Jowett, 2003; Mérigoux et al., 2009), or the level of food availability (Dobson and Hildrew, 1992; Drake, 1984) are known as determinants for benthic invertebrate specialization. In the particular case of chironomid larvae, such examples of autoecological data are still critically scarce, due in part to the fact that larvae species identification is time-consuming and requires sound taxonomic expertise (Pinder, 1986; Puntí et al., 2009). This notwithstanding, a few pioneer studies, and some other relatively recent ones, showed that the larvae distribution of several chironomid species is also primarily caused by both small-scale differences in substrate type (Epele et al. 2012) and hydraulic conditions 
(Collier, 1993; Ruse, 1994; Fesl, 2002; Syrovátka et al., 2009). Hydraulic variables might be more directly relevant than hydrologic ones with respect to stream biota and have been used to explain variations in biological condition (Statzner et al., 1988; Jowett et al., 1991). Interestingly, Syrovátka et al. (2009) reported similar hydraulic preferences in some congeneric species, however, to date no study has explored in depth the niches and spatial distribution of congeneric chironomid larvae. Despite the similarities in morphological and physiological characteristics between congeneric chironomid species, we hypothesize that fine-tuned adaptations to slightly different microhabitats could lead to non-equivalent niches and thus promote co-existence in heterogeneous environments. Indeed, understanding how the ecological niches of these species can contract, expand or persist as a consequence of changes in biological interactions and time-varying hydrological conditions, such as those occurring in Mediterranean streams (Gasith and Resh, 1999), could help to explain niche differentiation and co-occurrence of congeneric species.

In this contribution, we studied the assemblage of chironomid larvae in a small Mediterranean river to i) explore the co-occurrence of congeneric species, ii) to characterize their ecological niches, on the basis of hydraulic and substrate preferences at the scale of microhabitat, iii) to quantify the degree of niche overlap between congeneric species, and iv) provide insights of niche shifts in relation to seasonal changes in a river with variable hydrology.

\section{METHODS}

\section{Study system}

The study system (Fig. 1) was the Vallcebre catchment (31T 402900E; 4672559N), which includes an area of 19 $\mathrm{km}^{2}$ and is located in a mountainous area at a moderate altitude (around $1100 \mathrm{~m}$ asl in the pre-Pyrenees range) in a.

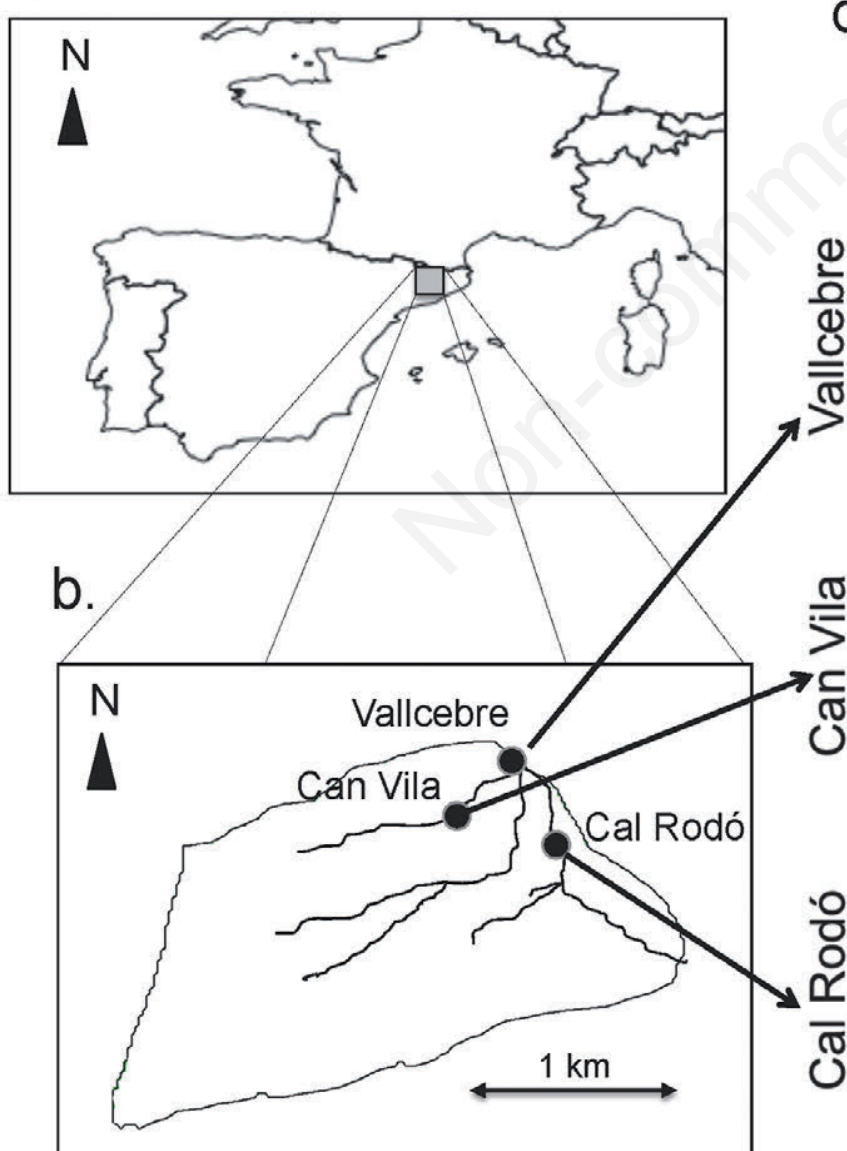

C.

\section{Flowing phase (Eurheic)}
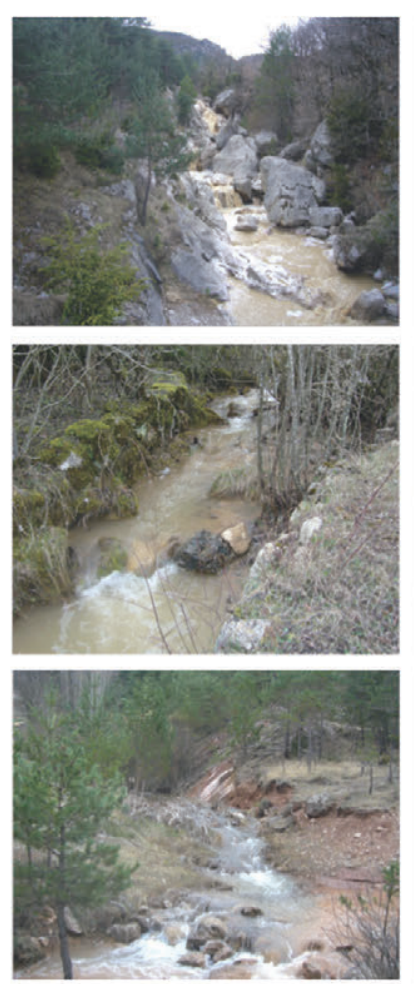

Dry phase

(Arheic)
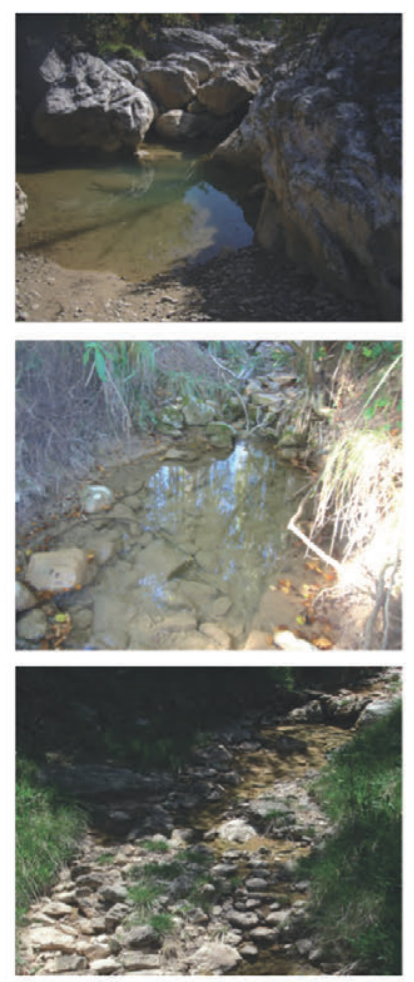

Fig. 1. Characterization of study sites including (a) location in Europe, (b) position within the Vallcebre catchment, and (c) photographs of the three sites under eurheic and arrheic conditions. 
the headwaters of the Saldes River, a tributary of the Llobregat River (NE Iberian Peninsula). Annual rainfall in the catchment is about $860 \mathrm{~mm}$ and annual potential evapotranspiration is $820 \mathrm{~mm}$ (Latron et al., 2009). During the summer, however, evapo-transpiration largely exceeds precipitation, inducing a water deficit and thus the interruption of flow in many reaches (García-Roger et al., 2011). Consequently, we studied three different sites with different hydrology within the catchment, named Cal Rodó (CR, permanent), Can Vila (CV, intermittent), and Vallcebre (V, intermittent), at two different seasons: i) spring, when pool-riffle sequences were well-established at all sites, and ii) summer, when flow was typically interrupted in the intermittent sites and water there was restricted to isolated pools (Fig. 1). These two seasons roughly correspond to eurheic and arrheic aquatic states, as defined for the studied sites in a previous paper by Cid et al. (2016).

\section{Sampling and microhabitat characterization}

In order to collect chironomid larvae and associate them to specific substrates and hydraulic conditions, we took 20 minisurbers $(15 \mathrm{~cm} \mathrm{x} 15 \mathrm{~cm} ; 250 \mu \mathrm{m}$ mesh) per site and season in the years 2009 and 2010. This made up a total of 240 (20 minisurbers per site $\mathrm{x} 3$ sites per season $\mathrm{x} 2$ seasons per year $\mathrm{x} 2$ years) minisurber samples, which were previously assigned to the different substrates in proportion to their relative abundance along a $50-\mathrm{m}$ reach for each site (García-Roger et al., 2011, 2013). Substrates were classified regarding their organic-inorganic nature in the classes described in Tab. 1, according to the MIRAGE EU-project protocol (García-Roger et al., 2011).

At sampling season and year, we measured physicochemical variables including water temperature, dissolved oxygen, $\mathrm{pH}$ and conductivity at each site, using portable probes (WTW). Within a site, water depth and velocity were measured at every point where a minisurber sample was taken (i.e. 20 points), and so these two hydraulic variables were associated to each substrate. Velocity was measured using an OSS-PC1 current meter. The simple hydraulic measures of depth and velocity were used to calculate more complex hydraulic variables, in an effort to better identify the hydraulic microhabitats that might occur. Stream biota - and consequently chironomid larvae - probably respond to thresholds and durations of hydraulic conditions (Growns and Davis, 1994; Wadeson and Rowntree, 1998; Brooks et al., 2005). Thus, we considered Reynolds and Froude numbers. The Reynolds number $(R e)$ is a measure of turbulence while the Froude number $(F r)$ is used to define tranquil or sub-critical flow (where $F r<1$ ) versus rapid or super-critical flow (where $\mathrm{Fr}>1$ ) (Chow, 1959). Both variables have been demonstrated to be useful in discriminating aquatic habitats and in the specialization of benthic invertebrates (Orth and Maughan, 1983; Jowett et al., 1991). The two variables were computed as follows:

$$
R e=\frac{v \times d}{v}
$$

Where $v$ is the mean current velocity (in $\mathrm{cm} \mathrm{s}^{-1}$ ), $d$ is depth (in $\mathrm{cm}$ ), and $v$ is the temperature-dependent kinematic viscosity (in $\mathrm{cm}^{2} \mathrm{~s}^{-1}$ ). The values of $u$ for the different temperatures recorded at each site and sampling occasion were obtained after Dingman (1984). And

$$
F r=\frac{v}{(d \times g)^{1 / 2}}
$$

Where $v$ and the $d$ stand as in the previous equation, and $g$ is the acceleration due to gravity $\left(9.8 \mathrm{~m} \mathrm{~s}^{2}\right)$.

\section{Sample processing: Chironomid species identification and counting}

Once collected, samples were fixed with formaldehyde ( $4 \%$ final concentration), brought to the laboratory and examined under a stereoscope. All

\begin{tabular}{|c|c|c|}
\hline \multicolumn{2}{|l|}{ Substrate } & Code \\
\hline \multicolumn{3}{|l|}{ Organic } \\
\hline \multicolumn{2}{|l|}{$\begin{array}{l}\text { Algae - Filamentous algae, algal tufts } \\
\text { Submerged macrophytes (including bryophytes) }\end{array}$} & $\mathrm{AL}$ \\
\hline \multicolumn{2}{|l|}{ Living part of terrestrial plants - Fine roots, floating ripatrian vegetation } & $\mathrm{TP}$ \\
\hline \multicolumn{2}{|l|}{ CPOM - Deposits of coarse particulate organic matter } & $\mathrm{CP}$ \\
\hline \multicolumn{2}{|l|}{ FPOM - Deposits of fine particulate organic matter } & $\mathrm{FP}$ \\
\hline Argyllal $(<6 \mu \mathrm{m})$ & Clay & ARG \\
\hline Akal $>(2 \mathrm{~mm}$ to $2 \mathrm{~cm})$ & Gravel & AKA \\
\hline Microlithal $(>2 \mathrm{~cm}$ to $6 \mathrm{~cm})$ & Coarse Gravel - Pebble & MIL \\
\hline Mesolithal $(>6 \mathrm{~cm}$ to $20 \mathrm{~cm})$ & Cobble & MEL \\
\hline Macrolithal $(>20 \mathrm{~cm}$ to $40 \mathrm{~cm})$ & Block & MAL \\
\hline Megalithal $(>40 \mathrm{~cm})$ & Boulder & MGL \\
\hline
\end{tabular}

Tab. 1. List and description of substrates found in this study (for more details see García-Roger et al., 2011). 
chironomid larvae were grouped in morphotypes according to Prat and Rieradevall (2014) and counted. When present, pupae were also isolated.

The identification of chironomid larvae was done at the lowest possible taxonomic resolution (genus or species) by using the diagnose keys provided by Hirvenoja (1973), Wiederholm (1983), Nocentini (1985), Schmid (1993), and the personal collection of the senior author of this paper that includes the association of pupae with larvae.

\section{Data analysis}

As a general procedure, abundance data of identified genera and species of chironomid larvae were reported as density values (individuals $\mathrm{m}^{-2}$ ), and hydraulic variables were standardized in order to properly deal with metrics of different magnitudes. All statistical analyses described below were carried out using functions and packages from R v 3.3.3 free statistical software (R Development Core Team, 2011).

First, we used Discriminat Correspondence Analysis (DCA) on chironomid larvae log-abundance, in order to explore the spatial and temporal variability of chironomid assemblages. As the name indicates, DCA is an extension of discriminant analysis (DA), and correspondence analysis (CA), that aims to categorize observations into predefined groups (Abdi, 2007). Specifically, we looked for differentiation patterns in the DCA ordination space among chironomid larvae assemblages when associated with the following factors: i) site (with three levels: CR, $\mathrm{CV}$, and $\mathrm{V}$ ); ii) substrate (with 11 levels, as described in Tab. 1); and iii) season (with two levels: spring and summer). DCA ordination was carried out by means of the dudi.coa function from the 'ade4' package (Dray and Dufour, 2007). Statistical differences among the levels of each factor of classification were assessed by means of Monte-Carlo randomization tests using 999 permutations with the $b c a$ and randtest functions from the same package.

To describe the ecological niches of congeneric chironomid larvae species we followed Hutchinson's (1957) niche concept, which considers the niche as an ndimensional hyperspace within which the larvae of the chironomid species can persist. Accordingly, we used the so-called Outlying Mean Index (OMI) method, which is a niche analysis designed for gradient studies, in which the variance in species abundance is maximized along ordination axes derived from environmental data input (Dolédec et al., 2000). Since the OMI method allows for the combined use of ordered factors and co-variates, we used both the hydraulic variables and substrate types as descriptors of the multi-dimensional hyperspace, herein summarized in Principal Components Analysis (PCA). Prior to PCA, hydraulic variables were scaled and those highly correlated (Pearson's $r>0.80$ ) were removed. Thereafter, the OMI method was applied for each of the different assemblages of congeneric chironomid larvae species identified, with only two restrictions, namely: i) being found in $\geq 4$ samples, and ii) accounting for $n \geq 20$ individuals. The following niche parameters were computed and tested for each species within the congeneric assemblage fulfilling this criterion: i) marginality, which represents the deviation of a given species' average position from the sampled area's average habitat conditions, and ii) tolerance, which is a measurement of niche breadth associated with the environmental variables. The statistical significance of the marginality was evaluated with a Monte Carlo permutation test $(\mathrm{n}=999)$, under the null hypothesis that each species, and the whole congeneric assemblage, are unrelated to their environment. Adjustment for multiple testing was applied using the Benjamini-Hochberg false discovery rate set at $5 \%$. All computations were carried out by means of the dudi.pca and niche functions within the 'ade4' package (Dray and Dufour, 2007).

We decomposed the niches of each congeneric species into spring and summer sub-niches by means of the Within Outlying Mean Index (WitOMI), which refines the OMI method by using its properties in combination with the K-select analysis species marginality decomposition (Karasiewicz et al., 2017). The WitOMI approach offers new interpretations to niche dynamics by allowing the consideration of habitat subsets within which the species sub-niches are developed. The advantage of this method is that sub-niches are comparable to the same environmental gradient, showing i) the shifting of niche throughout fluctuating habitat conditions, and ii) the difference between the potential sub-niche and the realized sub-niche. WitOMI analysis was performed using the sub-niche function from the 'sub-niche' package (Karasiewicz et al., 2017).

Niche overlap was estimated based on the reduced PCA dimensions of OMI niches using the analytical approach of Geange et al. (2012). Given the continuous nature of niche dimensions, the degree of niche overlap (NO) for each axis $t$ was based on non-parametric kernel density functions and computed as:

$$
\mathrm{NO}_{i j t}=1-0.5 \int\left|f_{i t}(\mathrm{x})-f_{j t}(\mathrm{x})\right| d x,
$$

Where $f_{i t}$ and $f_{j t}$ are the kernel population, density functions for the congeneric pair of species $i$ and $j$, respectively. A final niche overlap value was calculated by averaging niche overlap over each different axis. To assess the statistical niche differences between species, null model permutation tests $(\mathrm{n}=999)$ were performed to test whether the mean niche overlap was significantly higher than expected by chance (Geange et al., 2012). 
Niche overlap calculations based on kernel density estimates were carried out with the density function from the 'stats' package (R Development Core Team, 2011), and associated null model tests were performed using the $\mathrm{R}$ source code provided as supporting information in Geange et al. (2012). To correct for multiple comparisons, we repeated the Benjamini-Hochberg approach (Quinn and Keough, 2002). Finally, the co-occurrence between $i j$ pairs of congeneric chironomid larvae species found in our study was evaluated using Schoener's $\mathrm{D}_{i j}$ metric (Schoener, 1970), whose expression is as follows:

$$
\mathrm{D}_{i j}=1-0.5 \Sigma_{x}\left|p_{i x}-p_{j x}\right|
$$

Where $p_{i x}$ is the proportion of species $i$ at site (here, minisurber sample) $x$, and $p_{j x}$ is the proportion of species $j$ at the same site $x$. Schoener's $\mathrm{D}_{i j}$ takes values from 0 (when a given pair of species never coexists at any site) to 1 (when a given pair of species appears in all the same samples sites). Computation of $\mathrm{D}_{i j}$ was performed by means of the species.dist function from the 'picante' package (Kembel et al., 2010).

\section{RESULTS}

\section{Chironomid larvae assemblages}

We counted a total of 12,403 chironomid larvae belonging to 72 taxa from the total amount of minisurber samples, from the three sites studied in 2009 and 2010, with $96 \%$ of taxa being identified to the genus or species level, and ca. $60 \%$ within them achieving species level identification. A list with the most abundant taxa is shown in Tab. 2.

The multivariate ordination of samples based on DCA for the log-abundance of taxa revealed gradients along the first two axes (accounting for $27.34 \%$ of total inertia; Fig. 2). The observed distribution of samples could be partly explained by differences in chironomid larvae assemblages among the study sites (between-class variance $=0.079, \mathrm{P}=0.001$; Fig. $2 \mathrm{a}$ ), but also between seasons (between-class variance $=0.039 ; \quad \mathrm{P}=0.001$; Fig. 2b), years (between-class variance $=0.055 ; \mathrm{P}=0.001$; Fig. 2c), and among particular substrates (between-class variance $=0.094, P=0.02$; Fig. $2 \mathrm{~d}$ ).

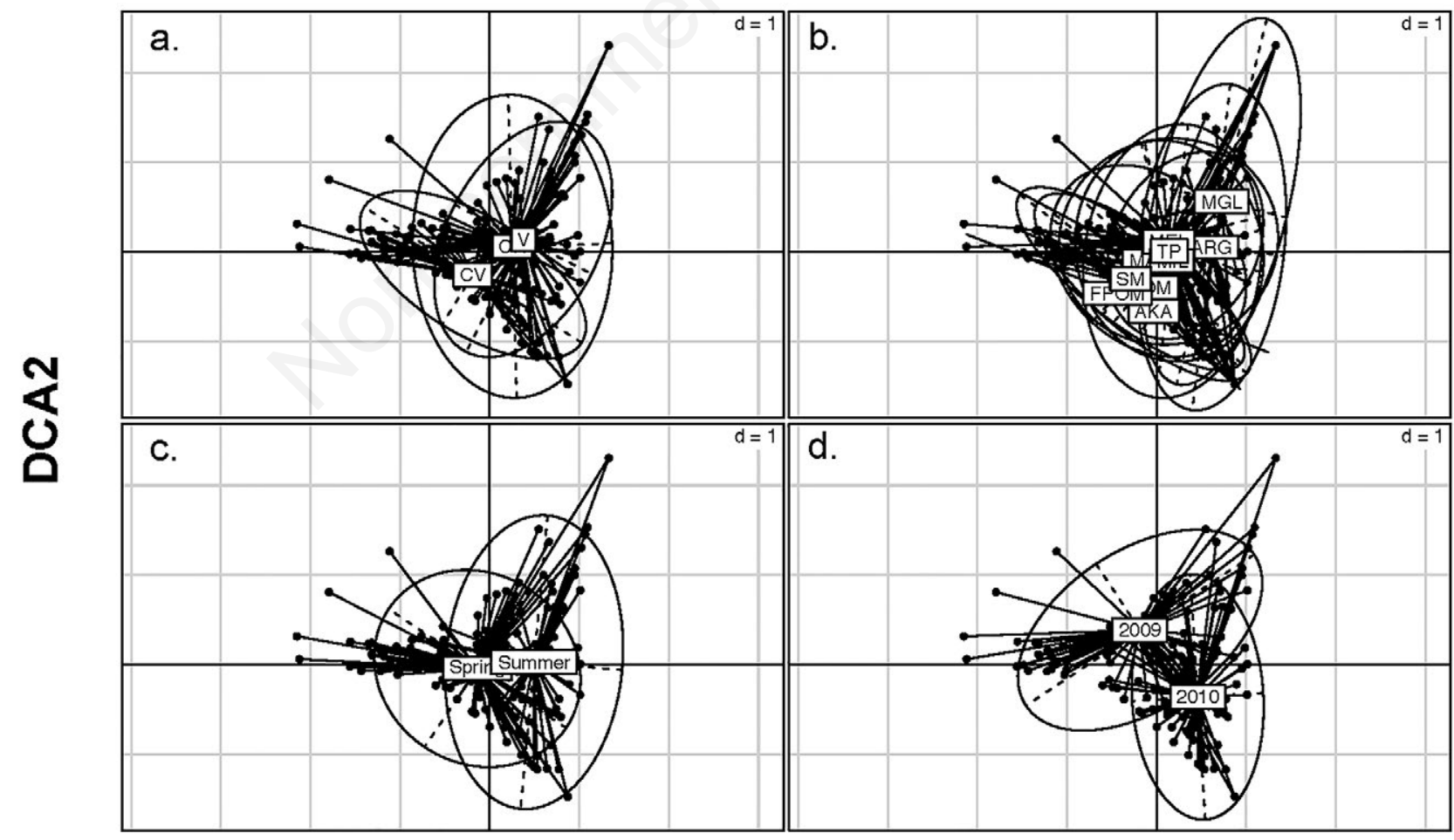

\section{DCA1}

Fig. 2. Ordination plot of minisurber samples after Discriminant Correspondence Analysis (DCA) on the log-abundances of chironomid larvae showing the $95 \%$ confidence ellipsoids for (a) study sites, (b) substrates, (c) seasons, and (d) years of study. 


\section{Niche analysis of congeneric species}

We considered 4 genera that included 2 or more species. This was the case of Eukiefferiella, with 7 species (E. cf devonica, E. claripennis, E. coerulescens, E. gracei, E. ilkleyensis, E. lobifera, and E. minor), Rheocricotopus, with 3 species ( $R$. chalybeatus, R. effusus, and $R$. fuscipes), and Orthocladius and Cricotopus, with two species each $(O$. rubicundus and $O$. wetterensis, and Cricotopus sp.1 and Cricotopus sp.2). In the case of Cricotopus larvae, we initially identified three species as C. bicinctus, C. albiforceps, and C. trifascia. The first was

Tab. 2. List of the most abundant taxa ( $\mathrm{n} \geq 20$ ind. for both years) for the different years and seasons sampled. Numbers in parenthesis indicate number of samples.

\begin{tabular}{|c|c|c|c|c|}
\hline Taxa & Spring 2009 & Summer 2009 & Spring 2010 & Summer 2010 \\
\hline Ablabesmyia & $7(6)$ & $13(6)$ & $5(3)$ & $0(0)$ \\
\hline Brillia modesta & $34(12)$ & $7(3)$ & $36(16)$ & $25(6)$ \\
\hline Chaetocladius & $0(0)$ & $0(0)$ & $23(6)$ & $2(2)$ \\
\hline Chironomus & $49(8)$ & $18(6)$ & $16(6)$ & $5(4)$ \\
\hline Conchapelopia & $27(9)$ & $27(8)$ & $18(9)$ & $14(3)$ \\
\hline Corynoneura & $725(44)$ & $360(35)$ & $600(42)$ & $231(36)$ \\
\hline Cricotopus sp 1 & $154(20)$ & $355(20)$ & $181(17)$ & $120(22)$ \\
\hline Cricotopus sp 2 & $47(6)$ & $210(6)$ & $588(43)$ & $232(36)$ \\
\hline Eukiefferiella cf devonica & $29(5)$ & $1(1)$ & $2(2)$ & $0(0)$ \\
\hline Eukiefferiella claripennis & $165(18)$ & $11(5)$ & $173(4)$ & $1(1)$ \\
\hline Eukiefferiella coerulescens & $101(16)$ & $14(3)$ & $39(10)$ & $0(0)$ \\
\hline Eukiefferiella gracei & $54(10)$ & $0(0)$ & $0(0)$ & $0(0)$ \\
\hline Eukiefferiella ilkleyensis & $20(2)$ & $0(0)$ & $0(0)$ & $0(0)$ \\
\hline Eukiefferiella lobifera & $0(0)$ & $5(1)$ & $17(3)$ & $0(0)$ \\
\hline Eukiefferiella minor & $201(31)$ & $66(6)$ & $550(35)$ & $53(5)$ \\
\hline Limnophyes & $4(1)$ & $0(0)$ & $8(5)$ & $10(3)$ \\
\hline Macropelopia & $57(18)$ & $0(0)$ & $16(6)$ & $1(1)$ \\
\hline Micropsectra & $930(41)$ & 737 (19) & $266(30)$ & $193(18)$ \\
\hline Microtendipes & $42(16)$ & $36(14)$ & $1(1)$ & $8(2)$ \\
\hline Nanocladius rectinervis & $38(12)$ & $1(1)$ & $8(4)$ & $14(4)$ \\
\hline Orthocladius rubicundus & $8(4)$ & $20(7)$ & $59(13)$ & $11(5)$ \\
\hline Orthocladius wetterensis & $64(13)$ & $63(11)$ & $71(13)$ & $58(13)$ \\
\hline Parakiefferiella & $\sqrt{n}$ & $1(1)$ & $7(1)$ & $13(6)$ \\
\hline Parametriocnemus stylatus & $265(29)$ & $119(17)$ & $61(17)$ & $77(21)$ \\
\hline Paraphenocladius & $18(4)$ & $0(0)$ & $0(0)$ & $4(1)$ \\
\hline Paratrichocladius & $23(4)$ & $1(1)$ & $26(7)$ & $7(2)$ \\
\hline Paratrissocladius excerptus & $60(21)$ & $30(11)$ & $29(10)$ & $49(14)$ \\
\hline Procladius & $137(15)$ & $3(3)$ & $15(3)$ & $0(0)$ \\
\hline Prodiamesa olivacea & $132(16)$ & $1(1)$ & $33(7)$ & $9(7)$ \\
\hline Rheocriccotopus chalybeatus & $0(0)$ & $2(1)$ & $0(0)$ & $36(8)$ \\
\hline Rheocricotopus effusus & $250(14)$ & $28(2)$ & $4(2)$ & $6(1)$ \\
\hline Rheocricotopus fuscipes & $316(31)$ & $113(14)$ & $304(23)$ & $38(14)$ \\
\hline Rheotanytarsus & $7(6)$ & $53(8)$ & $1(1)$ & $0(0)$ \\
\hline Saetheria & $8(5)$ & $13(6)$ & $29(7)$ & $56(11)$ \\
\hline Tanytarsus & $175(15)$ & $56(7)$ & $0(0)$ & $39(6)$ \\
\hline Thienemannimyia & $16(6)$ & $11(4)$ & $2(1)$ & $0(0)$ \\
\hline Trissopelopia & $48(14)$ & $21(6)$ & $41(10)$ & $24(5)$ \\
\hline Tvetenia calvescens & $34(13)$ & $0(0)$ & $0(0)$ & $1(1)$ \\
\hline Zavrelimyia & $28(12)$ & $171(26)$ & $25(6)$ & $157(18)$ \\
\hline
\end{tabular}


very scarce, while the other two were more abundant. Unfortunately, the albiforceps form was very variable and other individuals were not clearly classified in the different keys we used (Hirvenoja, 1973; Schmid, 1993), so we grouped Cricotopus in two clearly morphological species that failed to match exactly any of the species described in the available keys. The larvae of some of the chironomid species considered were associated to particular seasons (Tab. 2). For instance, E. claripennis and $R$. fuscipes were more abundant in spring samples than in summer ones. Other species, such as $O$. wetterensis, showed no preference in relation to the sampling season.

PCA underlying OMI niche analysis of the aforementioned assemblage of congeneric species was based on the main hydraulic variables, the different seasons, and substrates (Fig. 3). The first PCA axis was negatively related to Reynolds numbers, and positively to depth, thus representing a gradient from turbulent to quiet flow conditions. The projection of vectors on the ordination plot belonging to mineral substrates was consistent with this gradient extending from erosional (particle diameter $>16 \mathrm{~mm}$ according to Whitton, 1975; roughly corresponding to the MIL-MGL continuum) to depositional conditions (particle diameter $<1 \mathrm{~mm}$ according to Whitton, 1975; ARG substrate in our study). The second PCA axis served to differentiate organic substrates, especially algal (AL). The amount of total inertia accounted for by the two first axes was higher than $80 \%$ (55.9\% for the first axis, and $24.6 \%$ for the second). Total inertia was proportional to the average marginality and represents a quantification of the environmental variables influence on the niche separation of the studied species, thus confirming the appropriateness of this approach for our data.

In Fig. 4, we show the optima and tolerance of the aforementioned species for each PCA axis with respect to the origin of the ordination (i.e., average conditions of the habitat). Distance to the origin represents marginality (i.e., deviations from these conditions). For the first PCA axis, we observed that the aforementioned subset of congeneric chironomid larvae species ordered along the turbulentquiet flow gradient, with most of Eukieferiella congeneric species showing a preference for higher (Fig. 4a). The second PCA axis related species to different substrates (Fig. 4b). This clearly occurred for R. chalybeatus and algal substrates (AL), while the remainder of the species were almost equally present in substrates of very different natures.

Niche plots in both PCA dimensions are indicative of species distribution and environmental restrictions, but also niche overlap (which is discussed below). We observed that the larvae of the different Eukiefferiella congeneric species distributed along the turbulent-quiet

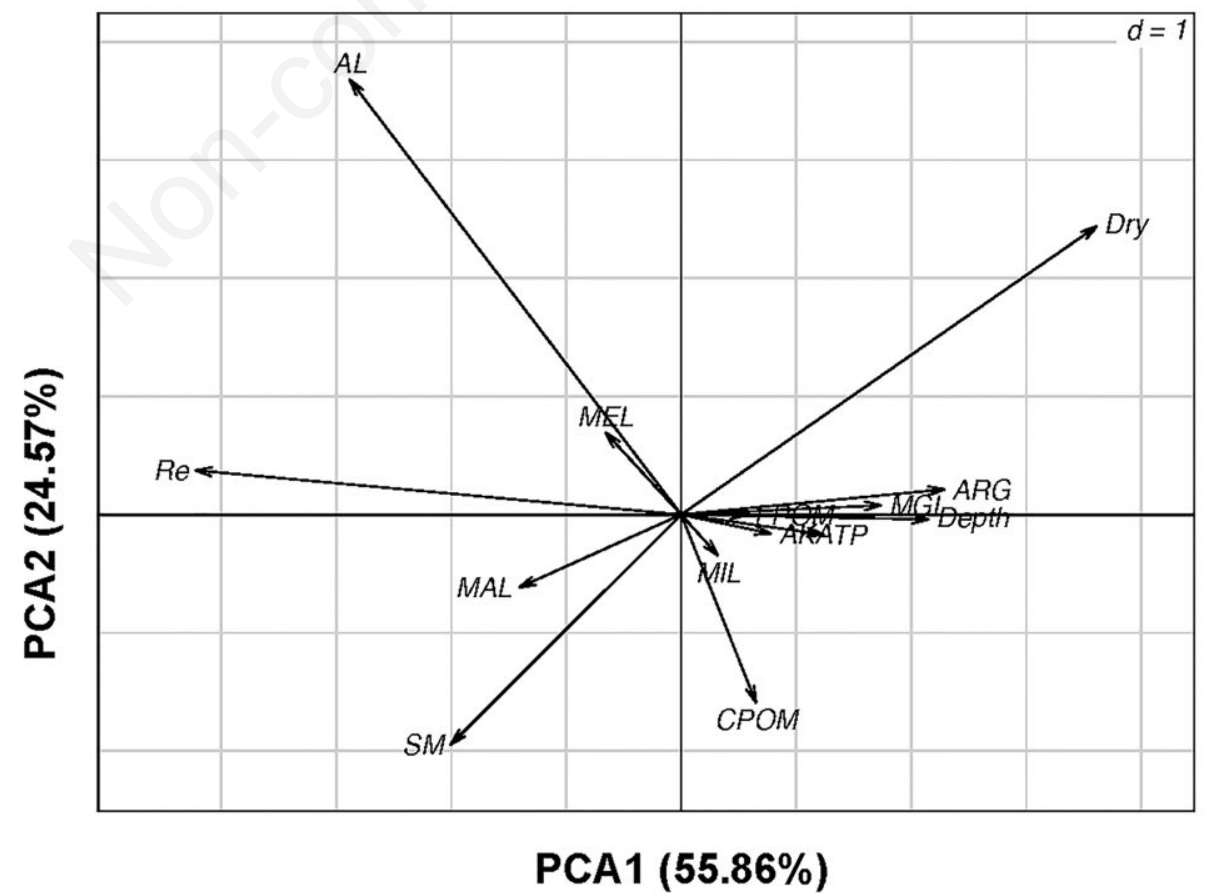

Fig. 3. Principal Component Analysis (PCA) plot showing the direction and strength of hydraulic variables and substrates in the ordination space. 
water flow gradient (i.e., the gravity center of the niche plots moved progressively to the right in the first PCA axis; Fig. 5 a-f). Marginality values were significantly different from 0 (i.e., the origin or reference point of the total niche space) in five out of six Eukiefferiella congeneric species, as determined by the Monte-Carlo randomization test and the Benjamini-Hochberg correction for multiple comparisons $(\mathrm{P}<0.05$ for all species, except $E$. lobifera with $\mathrm{P}=0.911$ ). The larvae of the three different Rheocricotopus congeneric species had dissimilar niche plots (Fig. 5 g-i), as they differed in the kind of substrate occupied (i.e., R. chalybeatus was found at samples with higher values in the second PCA axis than the other two species of this genus) and in velocity preferences (i.e., R. chalybeatus was present in samples with higher water fluxes, whereas $R$. fuscipes was present in samples with lower ones). Marginality was significant in $R$. chalybeatus and $R$. fuscipes $(\mathrm{P}<0.05)$, and marginally significant in $R$. effusus $(\mathrm{P}=0.055$, after Benjamini-Hochberg correction). Cricotopus and
Orthocladius species had very similar niche plots (Fig. S1), and only Cricotopus sp.1 exhibited significant marginality $(\mathrm{P}=0.039)$. The occurrence of the rest of species of the two genera did not significantly deviate from the average conditions in the habitat (i.e., $\mathrm{P}>0.05$ ).

Tab. 3 shows the values for niche overlap (NO) for the two main axes of OMI analysis and Schoener's D cooccurrence between pairs of the congeneric species found in our study. Values of $\mathrm{NO}$ averaged 0.764 across all comparisons, ranging from 0.651 (NO between $E$. coerulescens and $E$. devonica) to 0.905 (NO between Cricotopus sp.1 and Cricotopus sp.2). Schoener's D cooccurrence averaged 0.15 , and varied from 0 to 0.466 . The relationship between niche overlap and co-occurrence is depicted in Fig. 6. Correlation analysis between these variables revealed a significant, positive relationship (Pearson's $\mathrm{r}=0.632 ; \mathrm{t}=3.999, \mathrm{df}=24, \mathrm{P}<0.001$ ). We observed that the average number of co-occurring congeneric species varied among the four genera studied in relation to substrate type (Fig. 7). For Eukiefferiella

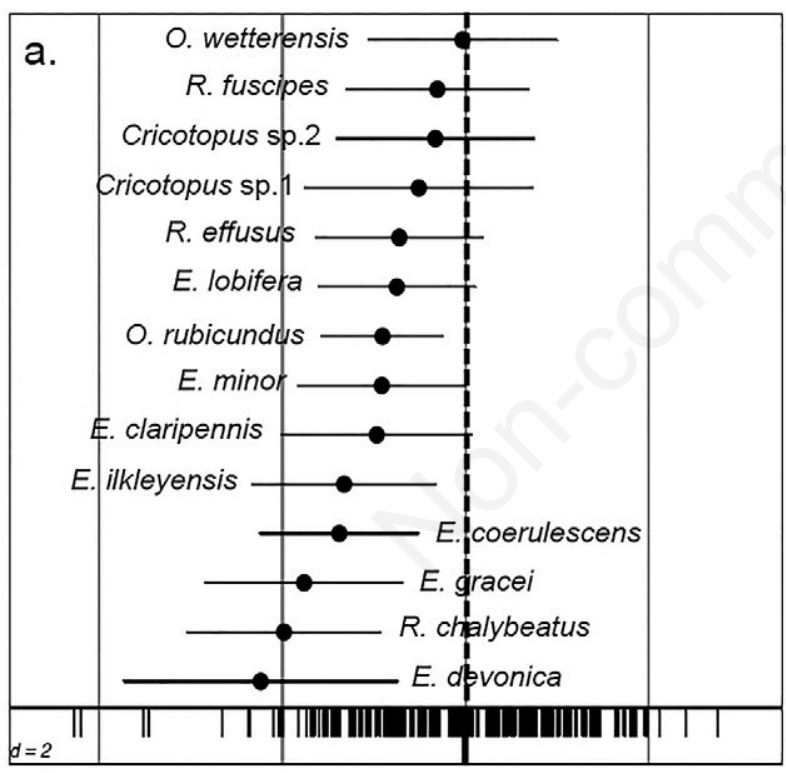

$\longleftarrow$ High Re

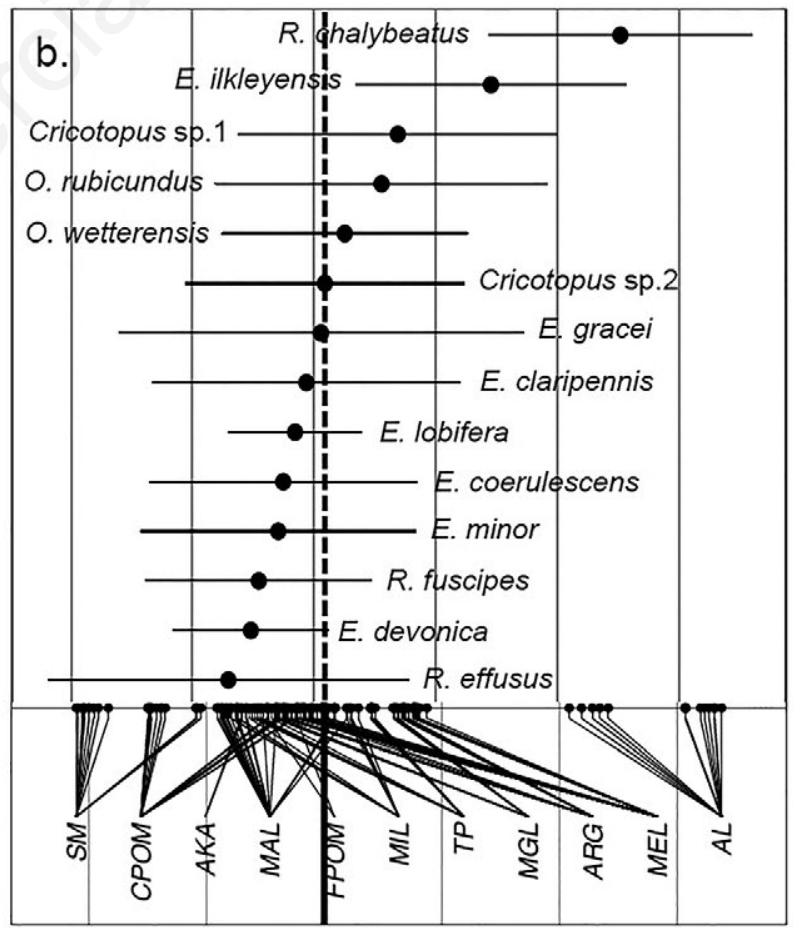

PCA2

Fig. 4. Position of the niches of chironomid larvae on the (a) first and (b) second PCA-based OMI components. The position of each taxa (dots) corresponds to the weighted mean of their distribution in sites and the horizontal lines are $95 \%$ quantiles representing a proxy of niche amplitude. The bottom vertical bars under panel (a) correspond to the minisurber sample scores along the gradient, with increasing Re from right to left. Dots under panel (b) indicate scores of minisurber samples along the second PCA axis, and lines link each minisurber sample with its corresponding substrate type. The vertical dashed lines across panels stand for the theoretical position of a hypothetical species adapted to average conditions in the habitat. 
(Fig. 7a), algal (AL) substrate harbored both the highest number of co-occurring larvae species (with an average of 3.75 congeneric species per sample) and the highest densities (53.25 \pm 19.48 larvae per AL sample). This substrate also harbored the highest densities of Cricotopus larvae (47.00 \pm 17.10 larvae per AL sample). In general, the average numbers of co-occurring congeneric species of Cricotopus ( $1.19 \pm 0.04$ congeneric species per sample) Orthocladius ( $1.05 \pm 0.11$ congeneric species per sample) and Rheocricotopus $(1.07 \pm 0.13$ congeneric species per sample) were low, and to some extent independent of the substrate type (Fig. 7 b-d).

Niche overlap among all pairs of congeneric species of the four genera is summarized in a heat-map (Fig. 8), in which colors from yellow to red mean increasing overlap. In general NO values among the different chironomid genera were high. For instance, Cricotopus species highly overlapped with those of Orthocladius (average NO of 0.837 ) and Rheocricotopus (average NO of 0.828 ) but less so with Eukiefferiella (average NO of 0.720 ), although high overlap also occurred among the congeneric species within this last genus (average NO of 0.760). An analysis of variance confirmed that NO differed among the above-mentioned comparisons $\left(\mathrm{F}_{2,21}=19.232, \mathrm{P}<0.001\right)$, and Tukey post-hoc comparisons revealed that NO between Cricotopus and Eukiefferiella species was significantly lower than those of the two other comparisons (i.e., Cricotopus-Orthocladius and Cricotopus-Rheocricotopus; $\mathrm{P}<0.05$ in both cases).

Niche shift in the transition from eurheic to arrheic conditions

The WitOMI approach (Fig. 9 a-b) allowed the analysis of the sub-niches of the congeneric chironomid species in spring and summer, or in other words under eurheic and arrheic aquatic states, making them comparable along the same environmental gradient as

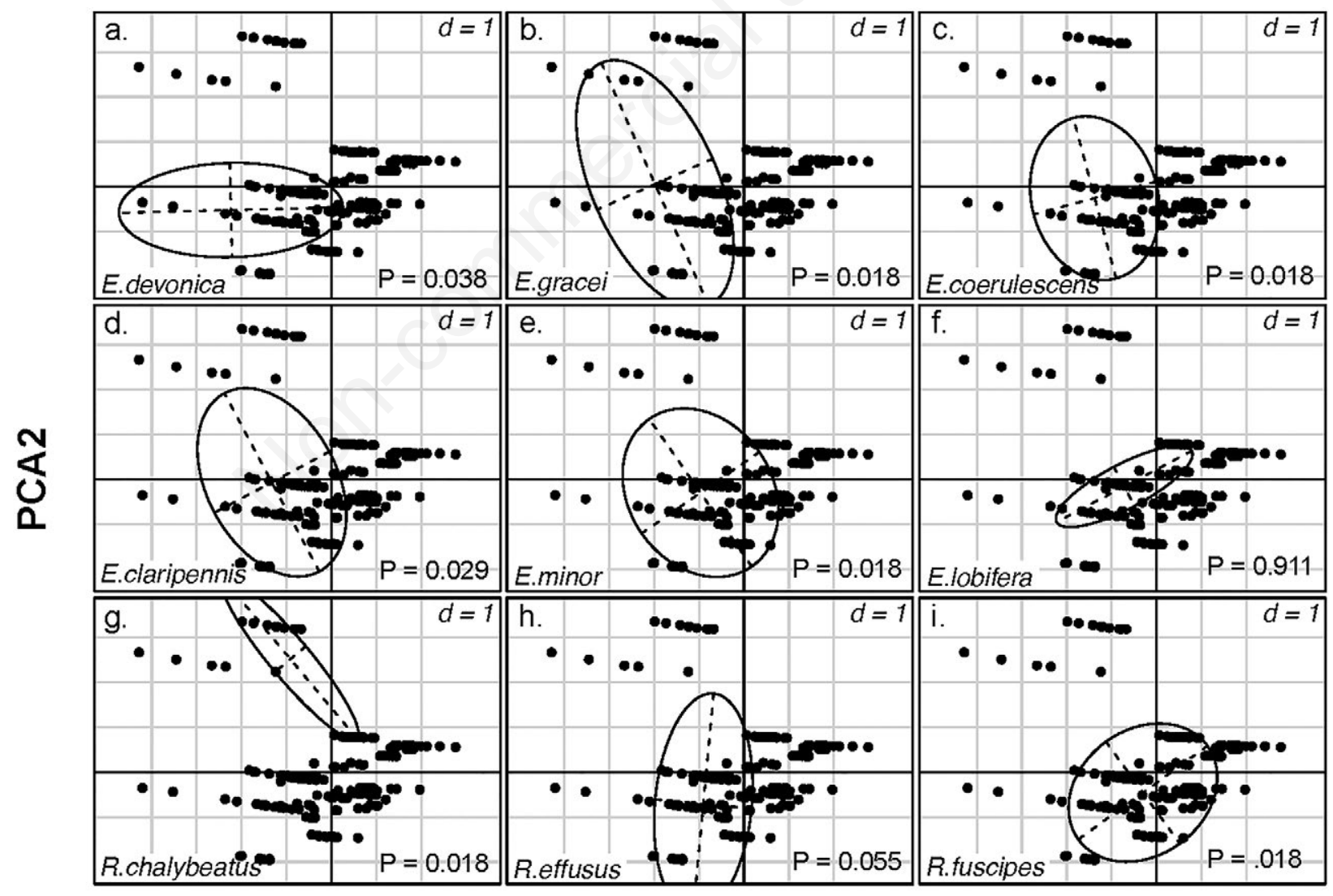

\section{PCA1}

Fig. 5. Niche plots of each of Eukiefferiella (a-f) and Rheocricotopus (g-i) species larvae according to the OMI analysis. Sites are represented as dots and lines link the center of gravity of each species to each site where larvae occurred. P represents significance of marginality values for the larvae of each species. 
both refer to the same original OMI analysis. The comparison of sub-niche positions demonstrated a general shift to lower values in the first axis of the OMI analysis, in the marginality of the different species, and more constrained habitat conditions in the transition from eurheic to arrheic regime.

\section{DISCUSSION}

Larvae of congeneric species of Cricotopus, Eukiefferiella, Orthocladius and Rheocricotopus coexisted in the three sites studied. These genera belong to the Orthocladiinae subfamily, whose larvae are typically associated with low water temperatures, and welloxygenated conditions (Pinder, 1995; Paggi, 2009). These larvae are similar in size (up to 6-8 $\mathrm{mm}$ ) and in their feeding requirements (mainly detritivores). These facts pose the question of how it is possible for them to cooccur, both considering the within-genus and among-genera assemblages. Here, we shed light on this question by applying the OMI and WitOMI approaches, a family of community-based analyses designed for gradient studies of ecological niches (Dolédec et al., 2000; Karasiewicz et al., 2017). It was not our intention to report on the fundamental niches of the aforementioned congeneric chironomid species, as this is largely inestimable (Panzacchi et al., 2014), but instead, these approaches allowed us to assess dissimilarities in microhabitat distributional patterns between these larvae. Interestingly, hydraulic features and substrates showed considerable variability even at the small spatial scale considered here. Thus, a not insignificant achievement of this study is that optima and tolerances have been estimated of those relevant environmental conditions requisite to obtain auto-ecological information - normally scarce - on a handful of congeneric chironomid species, and their lesser-dimensioned niches have been discriminated.

Tab. 3. Average niche overlap (NO) and Schoener's co-occurrence (D) among pairs of congeneric species of chironomids found in this study.

\begin{tabular}{|c|c|c|c|c|}
\hline Genus & Species 1 & Species 2 & NO & D \\
\hline Cricotopus & Cricotopus sp.1 & Cricotopus sp.2 & $0.905^{*}$ & 0.395 \\
\hline \multirow[t]{21}{*}{ Eukiefferiella } & E. claripennis & E. coerulescens & $0.738^{*}$ & 0.204 \\
\hline & & E. devonica & $0.640^{*}$ & 0.048 \\
\hline & & E. gracei & $0.769^{*}$ & 0.328 \\
\hline & & E. ilkleyensis & 0.730 & 0.080 \\
\hline & . & E. lobifera & 0.765 & 0.449 \\
\hline & (3) & E. minor & $0.836^{*}$ & 0.466 \\
\hline & E. coarulescens & E. devonica & $0.651^{*}$ & 0.038 \\
\hline & 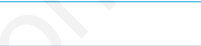 & E. gracei & 0.790 & 0.065 \\
\hline & 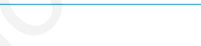 & E. ilkleyensis & 0.761 & 0.019 \\
\hline & & E. lobifera & 0.804 & 0.045 \\
\hline & & E. minor & $0.835^{*}$ & 0.353 \\
\hline & E. devonica & E. gracei & 0.729 & 0.068 \\
\hline & & E. ilkleyensis & 0.686 & 0.000 \\
\hline & & E. lobifera & 0.660 & 0.031 \\
\hline & & E. minor & $0.681^{*}$ & 0.085 \\
\hline & E. gracei & E. ilkleyensis & 0.865 & 0.370 \\
\hline & & E. lobifera & 0.775 & 0.000 \\
\hline & & E. minor & 0.852 & 0.129 \\
\hline & E. ilkleyensis & E. lobifera & 0.717 & 0.000 \\
\hline & & E. minor & 0.773 & 0.045 \\
\hline & E. lobifera & E. minor & $0.898^{*}$ & 0.243 \\
\hline Orthocladius & O. rubicundus & O. wetterensis & $0.787^{*}$ & 0.164 \\
\hline \multirow[t]{3}{*}{ Rheocricotopus } & R. chalybeatus & R. effusus & $0.721^{*}$ & 0.021 \\
\hline & & R. fuscipes & $0.709^{*}$ & 0.016 \\
\hline & R. effusus & R. fuscipes & $0.788^{*}$ & 0.125 \\
\hline
\end{tabular}

\footnotetext{
*Average niche overlap significance after null model permutation tests $(n=999)$ and Benjamini-Hochberg correction.
} 


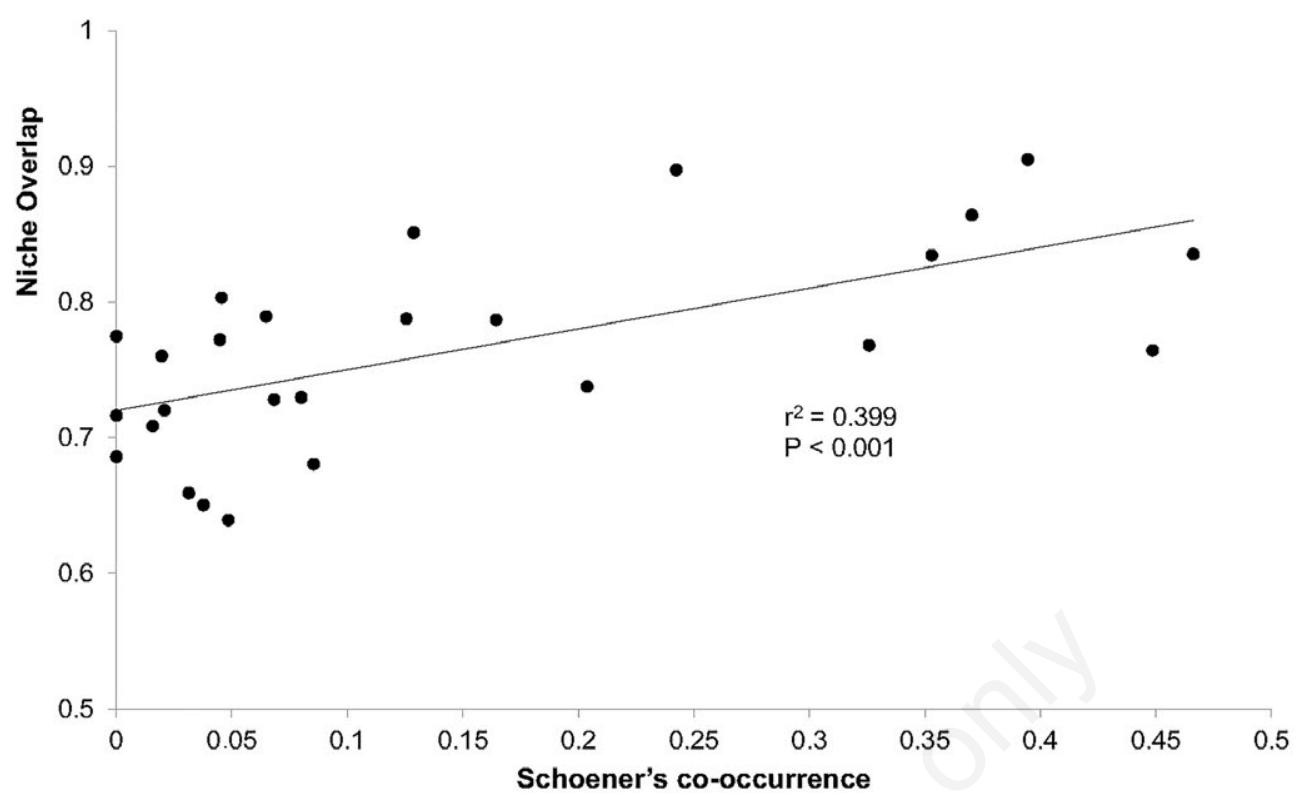

Fig. 6. Relationship between niche overlap and Schoener's co-occurrence for pairs of congeneric chironomid larvae found in this study.

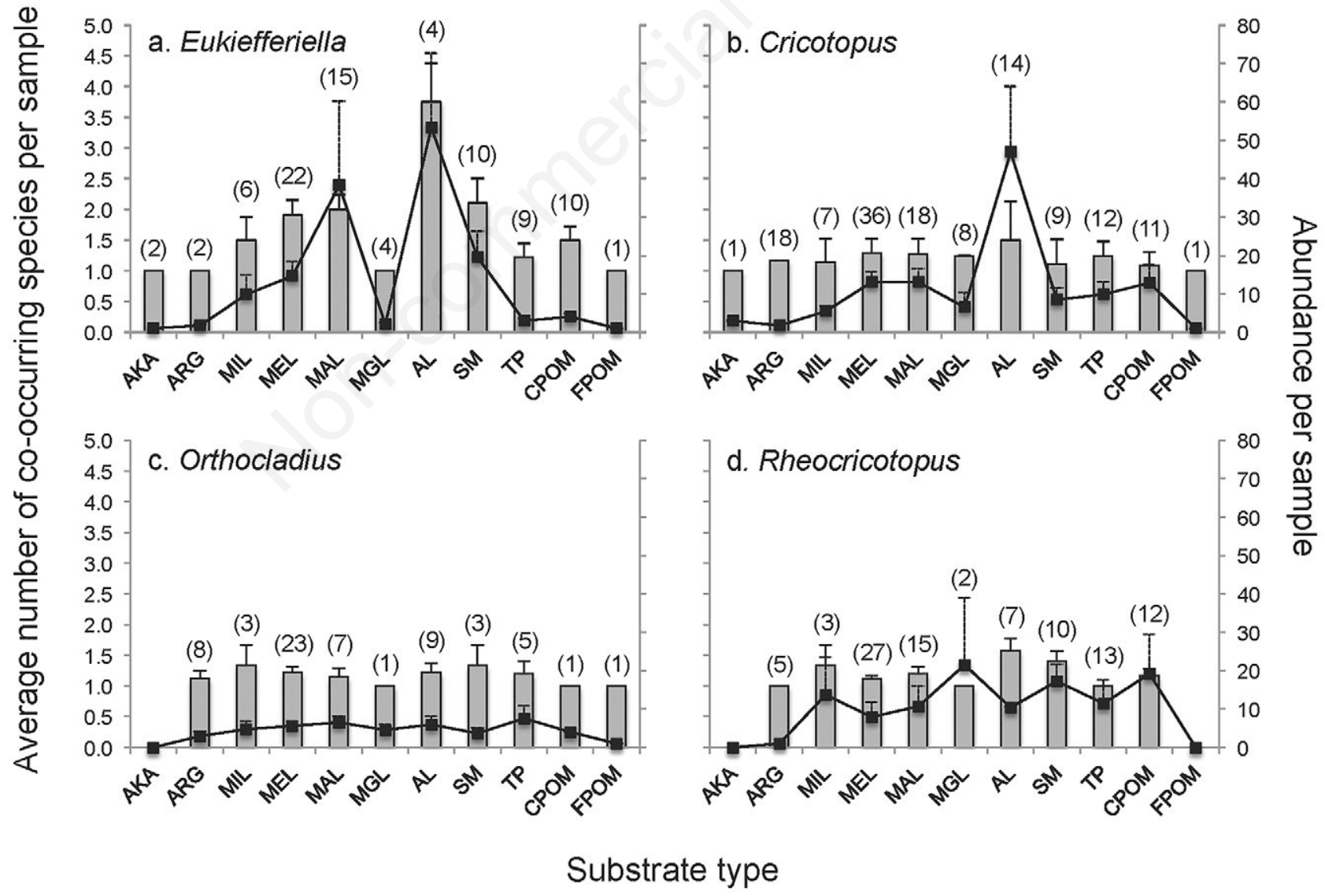

Fig. 7. Average number of co-occurring congeneric species of chironomid larvae (principal vertical axis) for (a) Eukiefferiella, (b) Cricotopus, (c) Orthocladius, and (d) Rheocricotopus under different substrates. Height of columns indicates averages and the solid bars are their corresponding standard errors. The secondary vertical axis measures larvae abundance per sample, with dots representing average values and dashed bars their corresponding standard errors. 
Although described as a reophilic genus (Cranston et al., 1983; Collier, 1993; Príncipe et al., 2008), the six Eukiefferiella congeneric species had variable optima and tolerances in relation to hydraulic conditions, mainly expressed in terms of water velocity and the Froude number. Thus, for instance, larvae of $E$. devonica and $E$. gracei showed significant preference for higher velocity than other congeneric, whereas E. lobifera occurred close to average hydraulic conditions in the study habitat with a narrow niche, all being consistent with findings from other studies, in which the two former species have been associated to riffle habitats and the latter to run habitats (Syrovátka et al., 2009). No particular discrimination in relation to substrate type was noticed among the species within this genus. Other environmental variables such as bedrock or altitude were not considered in our study because of the small spatial scale covered, but interestingly other studies showed that larvae of $E$. coerulescens are mostly found at higher altitudes and siliceous catchments, whereas E. devonica and E. minor inhabited preferably mid-altitude streams, and E. gracei and E. ilkleyensis are present in relatively low-altitude streams with a higher percentage of carbonates and higher temperature, flow and catchment area (Puntí et al., 2009).

Within the genus Rheocricotopus, $R$. chalybeatus was found across a wide range of the available hydraulic conditions, but exhibited a relatively narrow niche in the second axis of the OMI analysis, suggesting specific substrate requirements. Interestingly, this species was mainly found in AL substrates, whereas the two other congeneric $R$. effusus and $R$. fuscipes seemed relatively indifferent to the substrate type. These two species slightly

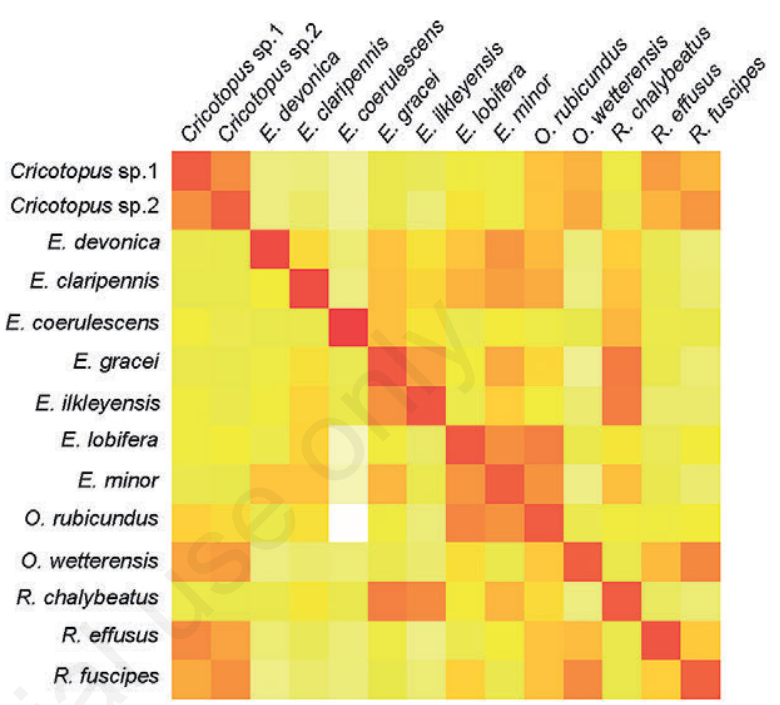

Fig. 8. Heat-map representing niche overlap among all pairs of chironomid species explored in this study. From yellow to red means increasing overlap.
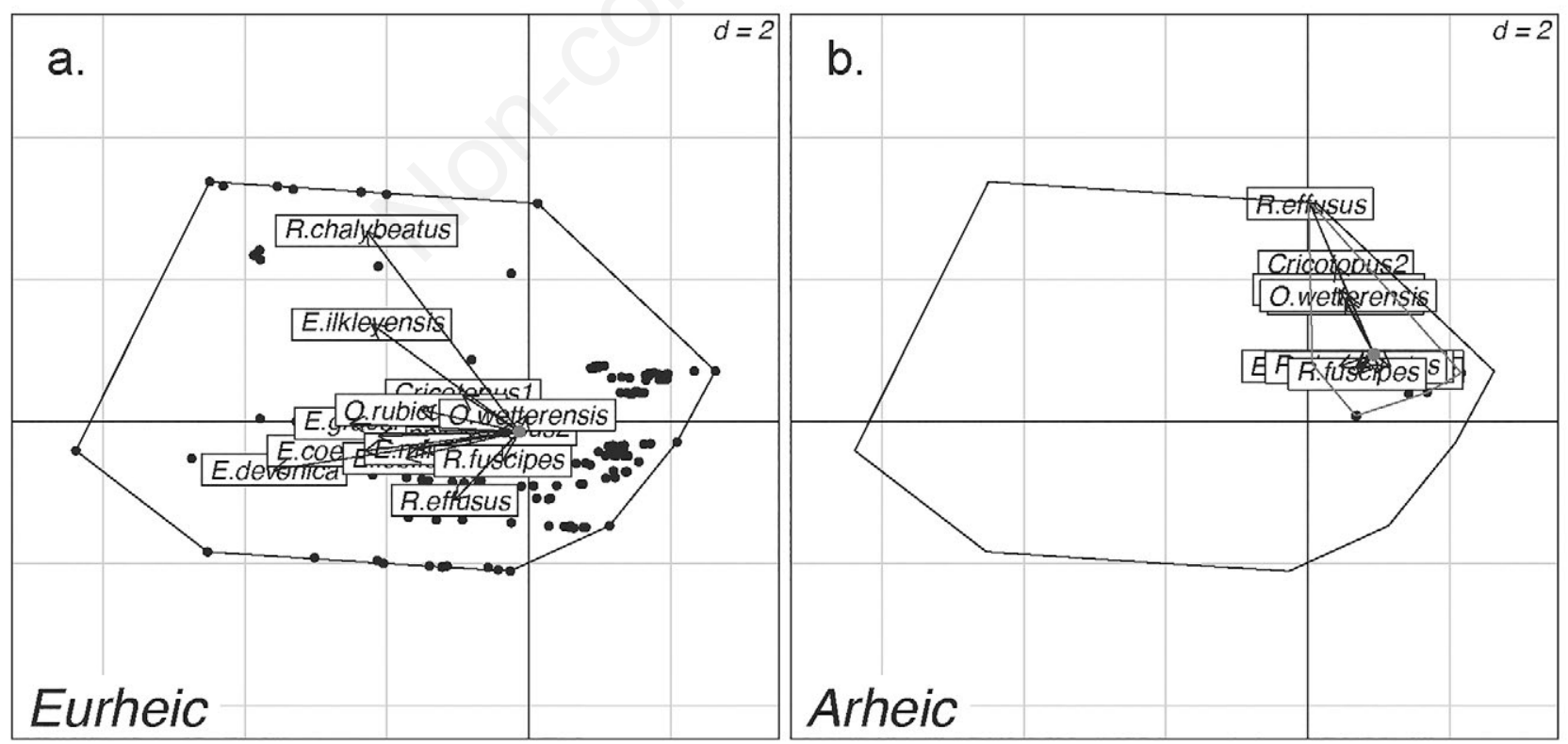

Fig. 9. Niche shift of congeneric chironomid larvae in the transition from (a) eurheic to (b) arrheic conditions. The full black-line polygon in both panels represents the maximum joint potential niche of the congeneric species of chironomid larvae studied, whereas the red-line polygons are subsetting the joint niche under habitat constraints for each aquatic state. The arrows represent WitOMI marginality for chironomid species with respect to average conditions (red dot) in each aquatic state. 
differed with respect to preferred hydraulic features, with $R$. effusus being less rheophilic than $R$. fuscipes.

Larvae of Cricotopus and Orthocladius are morphologically similar and are often studied as a species complex (Sinclair and Gresens, 2008). Notwithstanding, two morphospecies of Cricotopus (Cricotopus sp.1 and sp.2.) were considered, together with two well-defined species of Orthocladius (O. rubicundus and $O$. wetterensis). In the case of Cricotopus, we used morphospecies due to the difficulty in keying some specimens (see Results). Nevertheless, as the main interest of this paper was niche comparison, species' names were not important unless morphological species were associated to pupae. For Orthocladius, we also found specimens of two other species: O. obumbratus and $O$. rivulorum, which were clearly identified on the basis of taxonomical analysis for pupae and larval exuviae. However, the occurrence and abundance of these two other Orthocladius species were not sufficiently high to fulfill our niche analysis criteria (see Data analysis subsection in Methods). Not surprisingly we found that the niches of Cricotopus and Orthocladius exhibited a great similarity with high NO values, which can be explained given the morphological similarity between both genera, and the fact that hidden species diversity is likely to occur within Cricotopus. No particular discrimination in relation to hydraulic conditions or substrate was detected among the studied species or morphospecies of these two genera, all of them being found along the microlithal-megalithal (MIL-MGL) continuum or associated to deposits of organic matter. Although different substrates were expected to influence the feeding and behavior of aquatic invertebrates (Statzner et al., 1988), our results support the well-known flexibility in the feeding mode of Cricotopus and Orthocladius larvae (Syrovátka et al., 2009). The species within these two genera have been described as collectors, but also as periphyton grazers (Rossaro, 1992; Syrovátka et al., 2009), then having the ability to feed - and survive successfully in a wider range of hydraulic environments. Conversely, species with more specialised feeding modes would be expected to have more specific habitat preferences (Jowett, 2003).

Niche overlap assessment was completed by testing whether pairs of congeneric chironomid species also overlapped in geographical space. High niche overlap may lead to high competition and so to lower cooccurrence, according to MacArthur's (1972) prediction: "The more similar the competing species, the smaller their zone of geographic or habitat overlap". Strikingly, our results somewhat contrasted with theoretical expectations, as a positive relationship was observed between niche overlap and Schoener's (1970) co-occurrence D metric. This result could arise as a consequence of different processes. Thus for instance, the variable dynamics of the lotic environment (e.g., droughts, floods, temporal variability in resource distribution), or the effect of predators, might cause a reduction in chironomid larvae abundance so that competition would not take place and congeneric co-occurrence would be observed in a microhabitat, which is the spatial scale relevant for studies on competition (Holomuzki et al., 2010). On the other hand, the discovery of a relationship opposing the predicted one does not necessarily reject the hypothesis of competition, as i) this kind of biotic interaction could affect larvae distribution without producing total exclusion of a particular species (Abrams, 1984), and ii) transient co-existences are also possible (Anderson et al., 2008). However, co-occurrence values observed in our study were low in general ( 0.15 on average, in a $0-1$ scale), indicating that congeneric species actually are unlikely to co-exist. Indeed, average values of the numbers of co-occurring congeneric species per sample were close to one (Fig. 7), suggesting that co-occurrence of pairs of species is infrequent among samples, but can occur in particular substrates (e.g., AL substrate, which typically harbors higher numbers of co-occurring species and abundances). Since not all substrate types had the same quality in terms of food or refuge availability (Gregg and Rose, 1982; Dudley et al., 1986), we hypothesize that in poorer substrates, the presence of grazing larvae of a single chironomid species might severely limit the distribution of its potential competitors. Interestingly, this competition could occur at an early stage of habitat recolonization, with a lottery for available substrates operating at larvae settlement (Hemphill and Cooper, 1983). The likelihood of this random process is supported after seeing the differences between the two years studied, with species abundant in one year but not in the other. Among congeneric chironomid species, the one that comes first one year may not be the same in the following one, so that the difference in densities may simply be explained by which species came first. Whether or not competition for substrate is a major organizing force underlying the structure of these congeneric chironomid larvae assemblages, plus the role of larvae settlement timing, should be confirmed by means of experimental studies.

Fluctuating habitat conditions in Mediterranean intermittent streams often hamper defining ecological niches. Notwithstanding, the novel WitOMI approach allowed us to study niche dynamics by considering subsets of habitat conditions within which the species subniches developed (Karasiewicz et al., 2017). We found that larvae niches of the studied chironomid species generally clumped by shifting to lower flow velocities under arrheic conditions, so that niche overlap between pairs of congenerics increased by $4 \%$. The total number 
of chironomid species was lower under arrheic conditions but, as some species still persisted in the remaining pools, a $140 \%$ increase in average co-occurrence with respect to eurheic conditions was observed. Such a higher cooccurrence in summer pools could lead to complex interactions in which not only pairwise, but diffuse competition (MacArthur, 1972) among grazers might prove important. Note also that we have considered here a substrate effect on competition between chironomid species, but substrates might also differ in their quality depending in part on predation risk, and this could be higher in summer pools (Rodríguez-Lozano et al., 2015). Further work needs to be carried out in the future to analyze the influence of this factor.

\section{ACKNOWLEDGMENTS}

This study has been supported by the EU MIRAGE (Mediterranean Intermittent River MAnaGEment) project, with funds from the specific program 'Cooperation', theme 'Environment (including Climate Change)' under its $7^{\text {th }}$ Research Framework Program (FP7-ENV-2007-1, grant agreement 211732).

\section{REFERENCES}

Abdi H, 2007. Discriminant correspondence analysis (dca), p. 270-275. In: N.J. Salkind (ed.), Encyclopedia of measurement and statistics. Sage, Thousand Oaks.

Abrams PA, 1984. Foraging time optimization and interactions in food webs. Am. Nat. 124:80-96.

Anderson KE, Nisbet RM, McCauley E, 2008. The spatial-scale dependence of transient dynamics in streams and rivers. Bull. Math. Biol. 70:1480-1502.

Beisel JN, Usseglio-Polatera P, Moreteau JC, 2000. The spatial heterogeneity of a river bottom: A key factor determining macroinvertebrate communities. Hydrobiologia 422/423: 163-171.

Brooks AJ, Haeusler T, Reinfelds I, Williams S, 2005. Hydraulic microhabitats and the distribution of macroinvertebrates assemblages in riffles. Freshwater Biol. 50:331-344.

Chow VT, 1959. Open-channel hydraulics. McGraw-Hill, New York: 680 pp.

Chutter FM, 1969. The effect of silt and sand on the invertebrate fauna of streams and rivers. Hydrobiologia 34:57-76.

Cid N, Verkaik I, García-Roger EM, Rieradevall M, Bonada N, Sánchez-Montoya MM, Gómez R, Suárez ML, VidalAbarca MR, Demartini D, Buffagni A, Erba S, Karaouzas I, Skoulikidis N, Prat N, 2016. A biological tool to assess flow connectivity in reference temporary streams from the Mediterranean Basin. Sci. Total Environ. 594: 78-190.

Collier KJ, 1993. Flow preferences of larval Chironomidae (Diptera) in Tongariro River, New Zealand. N. Z. J. Mar. Freshw. Res. 27:219-226.

Cranston PS, Oliver DR, Sæther OA, 1983. The larvae of Orthocladiinae (Diptera: Chironomidae) of the Holartic
Region. Key and diagnoses. In: T. Wiederholm (ed.), Chironomidae of the Holartic Region: Keys and diagnoses. Entomologica Scandinavica.

Dingman SL, 1984. Fluvial hydrology. Freeman \& Co., New York: $383 \mathrm{pp}$.

Dobson M, Hildrew AG, 1992. A test of resource limitation among shredding detritivores in low order streams in southern England. J. Anim. Ecol. 61:69-71.

Dolédec S, Chessel D, Gimaret-Carpentier C, 2000. Niche separation in community analysis: A new method. Ecology 81:2914.

Drake JA, 1984. Species aggregation: the influence of detritus in a benthic invertebrate community. Hydrobiologia 112:109-115.

Dray S, Dufour AB, 2007. The ade4 package: implementing the duality diagram for ecologists. J. Stat. Softw. 22:1-20.

Dudley TL, Cooper SD, Hemphill N, 1986. Effects of macroalgae on a stream invertebrate community. J. N. Am. Benthol. Soc. 5:93-106.

Epele LB, Miserendino ML, Brand C, 2012. Does nature and persistence of substrate at a mesohabitat scale matter for chironomidae assemblages? A study of two perennial mountain streams in Patagonia, Argentina. J. Insect Sci. 12:68.

Fesl C, 2002. Biodiversity and resource use of larval chironomids in relation to environmental factors in a large river. Freshwater Biol. 47:1065-1087.

García-Roger EM, Sánchez-Montoya MM, Gómez R, Suárez ML, Vidal-Abarca MR, Latron J, Rieradevall M, Prat N, 2011. Do seasonal changes in habitat features influence aquatic macroinvertebrate assemblages in perennial versus temporary Mediterranean streams? Aquat. Sci. 73:567-579.

García-Roger EM, Sánchez-Montoya MM, Cid N, Erba S, Karaouzas I, Verkaik I, Rieradevall M, Gómez R, Suárez ML, Vidal-Abarca MR, Demartini D, Buffagni A, Skoulikidis N, Bonada N, Prat N, 2013. Spatial scale effects on taxonomic and biological trait diversity of aquatic macroinvertebrates in Mediterranean streams. Fundam. Appl. Limnol. 183:89-105.

Gasith A, Resh VH, 1999. Streams in Mediterranean climate regions: abiotic influences and biotic responses to predictable seasonal events. Annu. Rev. Ecol. Syst. 30:51-81.

Gause GF, 1934. The struggle for existence. Williams \& Wilkins, Baltimore: 163 pp.

Geange SW, Pledger S, Burns KC, Shima JS, 2012. A unified analysis of niche overlap incorporating data of different types. Meth. Ecol. Evol. 2:175-184.

Gregg WW, Rose FL, 1982. The effects of aquatic macrophytes on the stream microenvironment. Aquat. Bot. 14:309-324.

Growns IO, Davis JA, 1994. Longitudinal changes in near-bed flows and macroinvertebrate communities in a Western Australian stream. J. N. Am. Benthol. Soc. 13:417-438.

Hemphill N, Cooper SD, 1983. The effect of physical disturbance on the relative abundances of two filter-feeding insects in a small stream. Oecologia 58: 378-382.

Hirvenoja M, 1973. [Revision der Gattung Cricotopus van der Wulp und ihrer Verwandten (Diptera, Chironomidae)].[Book in German]. Societas Biologica Fennica Vanamo, Helsinki: $363 \mathrm{pp}$.

Holomuzki JR, Feminella JW, Power ME, 2010. Biotic 
interactions in freshwater benthic habitats. J. N. Am. Benthol Soc. 29:220-244.

Hutchinson GE, 1957. Concluding remarks. Cold Spring Harbor Symp. Quant. Biol. 22:415-427.

Jowett IG, 2003. Hydraulic constraints on habitat suitability for benthic invertebrates in gravel-bed rivers. River Res. Appl. 19:495-507.

Jowett IG, Richardson J, Biggs BJF, Hickey CW, Quinn JM, 1991. Microhabitat preferences of benthic invertebrates and the development of generalised Deleatidium spp. habitat suitability curves, applied to four New Zealand rivers. New Zeal. J. Mar. Fresh. 25:187-199.

Karasiewicz S, Dolédec S, Lefebvre S, 2017. Within outlying mean indexes: refining the OMI analysis for the realized niche decomposition. PeerJ 5:e3364.

Kembel SW, Cowan PD, Helmus MR, Cornwell WK, Morlon H, Ackerly DD, Blomberg SP, Webb CO, 2010. Picante: R tools for integrating phylogenies and ecology. Bioinformatics 26:463-1464.

Latron J, Llorens P, Gallart F, 2009. The hydrology of Mediterranean mountain areas. Geog. Compass 3:2045-2064.

Lencioni V, Rossaro B, 2005. Microdistribution of chironomids (Diptera: Chironomidae) in Alpine streams: an autoecological perspective. Hydrobiologia 533:61-76.

MacArthur RH, 1972. Geographical ecology. Harper \& Row, New York: 269 pp.

McLachlan A, 1993. Can two species of midge coexist in a single puddle of rainwater? Hydrobiologia 259:1-8.

Mérigoux S, Lamouroux N, Olivier JM, Dolédec S, 2009. Invertebrate hydraulic preferences and predicted impacts of changes in discharge in a large river. Freshwater Biol. 54:1343-1356.

Minshall GW, Minshall JN, 1977. Microdistribution of benthic invertebrates in a Rocky Mountain (U.S.A.) stream. Hydrobiologia 55:231-249.

Nocentini A, 1985. [Guide per il riconoscimento delle specie animali delle acque interne italiane. Chironomidi, 4. (Diptera: Chironomidae: Chironominae, larvae)].[Book in Italian]. AQ/1/ 233. Consiglio Nazionale delle Ricerche, Verona, Italy.

Orth DJ, Maughan OE, 1983. Microhabitat preferences of benthic fauna in a woodland stream. Hydrobiologia 106: 157-168.

Paggi AC, 2009. [Diptera Chironomidae], p. 383-409. In: E. Domínguez and H.R. Fernández (eds.), [Macroinvertebrados bentónicos sudamericanos. Sistemática y biología].[Book in Spanish]. Fundación Miguel Lillo, Tucuman.

Panzacchi M, van Moorter B, Strand O, Loe LE, Reimers E, 2014. Searching for the fundamental niche using individualbased habitat selection modelling across populations. Ecography 38:659-669.

Pinder LCV, 1986. Biology of freshwater Chironomidae. Ann. Rev. Entomol. 31:1-23.

Pinder LCV, 1992. Biology of epiphytic Chironomidae (Diptera: Nematocera) in chalk streams. Hydrobiologia 248:39-41.

Pinder LCV, 1995. The habitats of chironomid larvae, p. 107135. In: P.D. Armitage, P.S. Cranston and L.C.V. Pinder (eds.), The Chironomidae: Biology and ecology of non biting midges. Chapman and Hall, London.

Prat N, Rieradevall M, 2014. [Guía para el reconocimiento de las larvas de Chironomidae (Diptera) de los ríos mediterráneos].[Report in Spanish]. Available from: http://diposit.ub.edu/dspace/handle/2445/60584

Príncipe E, Boccolini MF, Corigliano MC, 2008. Structure and spatial-temporal dynamics of Chironomidae fauna (Diptera) in upland and lowland fluvial habitats of the Chocancharava River Basin (Argentina). Int. Rev. Hydrobiol. 93:342-357.

Puntí T, Rieradevall M, Prat N, 2007. Chironomidae assemblages in reference condition Mediterranean streams: environmental factors, seasonal variability and ecotypes. Arch. Hydrobiol. 170:149-165.

Puntí T, Rieradevall M, Prat N, 2009. Environmental factors, spatial variation and specific requirements of chironomidae in Mediterranean reference streams. J. N. Am. Benthol. Soc. 28:247-265.

Quinn GP, Keough MJ, 2002. Experimental design and data analysis for biologists. Cambridge University Press, Cambridge: $537 \mathrm{pp}$.

R Development Core Team, 2011: R: A language and environment for statistical computing. R Foundation for Statistical Computing, Vienna, Austria. Available from: http://www.R-project.org.

Rivas LR, 1964. A reinterpretation or the concepts "Sympatric" and "Allopatric" with proposal or the additional terms "Syntopic" and "Allotopic". Syst. Zool. 13:42-43.

Rodríguez-Lozano P, Verkaik I, Rieradevall M, Prat N, 2015. Small but powerful: top predator local extinction affects ecosystem structure and function in an intermittent stream. PLoS One 10: 0117630.

Rossaro B, 1992. Chironomidae from Italy. Chironomus Newsletter on Chironomidae Res. 4:19.

Rossaro B, Lencioni V, Boggero A, Marziali L, 2006. Chironomids from Southern Alpine running waters: ecology, biogeography. Hydrobiologia 562:231-246.

Ruse LP, 1994. Chironomid microdistribution in gravel of an English chalk river. Freshwater Biol. 32:533-551.

Schmid PE, 1993. A key to the larval Chironomidae and their instars from Austrian Danube region streams and rivers with particular reference to a numerical taxonomic approach. Part I. Diamesinae, Prodiamesinae and Orthocladiinae. Wasser Abwasser Suppl. 3/93:1-514.

Schoener TW, 1970. Nonsynchronous spatial overlap of lizards in patchy habitats. Ecology 51:408-418.

Sinclair CS, Gresens SE, 2008. Discrimination of Cricotopus species (Diptera: Chironomidae) by DNA barcoding. Bull. Ent. Res. 98: 55-563.

Statzner B, Gore JA, Resh, VJL, 1988: Hydraulic stream ecology: observed patterns and potential applications. J. N. Am. Benthol. Soc. 7:307-360.

Syrovátka V, Schenková J, Brabec K, 2009. The distribution of chironomid larvae and oligochaetes within a stony-bottomed river stretch: the role of substrate and hydraulic characteristics. Fund. Appl. Limnol. 174:43-62.

Tokeshi M, 1995. Production ecology, p. 269-292. In: P.D. Armitage, P.S. Cranston and L.C.V. Pinder (eds.), The Chironomidae: Biology and ecology of non biting midges. Chapman \& Hall, London.

Violle C, Reich PB, Pacala SW, Enquist BJ, Kattge J, 2014. The emergence and promise of functional biogeography. P. Natl. Acad. Sci. USA 111:13690-13696. 
Wadeson RA, Rowntree KM, 1998. Application of the hydraulic biotope concept to the classification of instream habitats. Aquat. Ecosyst. Health 1:143-157.

Wentworth CJ, 1922. A scale of grade and class terms for clastic sediments. J. Geology 30:377-392.

Whitton BA, 1975. River ecology. Studies in ecology 2. Blackwell Scientific Publications, Oxford: 725 pp.

Wiederholm MT, 1983. Chironomidae of the Holartic region: keys and diagnoses. Part 1. Larvae. Entomol. Scandin. Suppl. 19:1-457.

Wiens JJ, Ackerly DD, Allen AP, Anacker BL, Buckley LB, Cornell HV, Damschen EI, Davies JT, Grytnes J, Harrison SP, Hawkins BA, Holt RD, McCain CM, Stephens PR, 2010. Niche conservatism as an emerging principle in ecology and conservation biology. Ecol. Lett. 13: $1310-1324$ 